\title{
PERFIL MICROBIOLÓGICO DA CARNE MOÍDA COMERCIALIZADA NO MUNICÍPIO DE JUAZEIRO DO
} NORTE, CEARÁ

\section{ALMEIDA, Bruna S.*; MONTEIRO, Wagner A.; BEZERRA, Francisco Y.P.}

\author{
Faculdade Leão Sampaio - Juazeiro do Norte (CE), Brasil.
}

Recebido em: 22/01/2015; Aceito: 22/04/2015; Publicado: 25/08/2015

\section{RESUMO}

Devido seu alto teor proteico, e sua rica constituição de nutrientes essenciais ao metabolismo humano, a carne bovina é um dos alimentos mais consumidos pela população brasileira. Principal derivado cárneo, a carne moída é um alimento que possui alta demanda pela população brasileira, principalmente por apresentar um preço mais acessível que a carne in natura. Por ser um produto que passa por um longo processo de manipulação em seu preparo esse alimento está propenso a ser contaminado em alguma dessas etapas. $\mathrm{O}$ alimento contaminado pode ser um veículo de transmissão de doenças, o que pode acarretar problemas a população. Este estudo avaliou o perfil microbiológico da carne moída comercializada no município de Juazeiro do Norte- Ceará. Para a análise microbiológica foram coletadas 12 amostras de carne moída de estabelecimentos públicos e privados, sendo 6 de diferentes pontos comercias dos três principais mercados públicos da cidade, e as outras 6 amostras de frigoríficos privados. Os resultados apontam um elevado grau de contaminação desse alimento, com presença de bactérias como Klebsiella spp., Escherichia coli, Salmonella spp., além de contaminação parasitária e crescimento de fungos na forma de bolor e leveduriforme, na maioria das amostras analisadas, tanto provenientes de mercados públicos, quanto de comércio privado. Nota-se que de acordo com os resultados apontados esse alimento torna-se um veículo de transmissão de doenças para a população, por isso é imprescindível que haja um preparo de modo adequado para tornar esse produto propício para a alimentação humana.

Palavras-chave: Carne, Microrganismo, Contaminação.

\begin{abstract}
Because of its high protein content and rich constitution of essential nutrients to the human metabolism, beef is one of the foods consumed by the population. Main meat derived, ground beef is a food widely consumed by the population, mainly present more affordable than fresh beef. Being a product that goes through along process of manipulation in its preparation that food is likely to be contaminate of these steps. The contaminated food can be a vehicle for transmission of diseases, which can cause problems to the population. This study evaluated the microbiological profile of ground beef sold in Juazeiro do Norte - Ceará. For microbiological analysis of ground beef samples of public and private establishments were collected. The results indicate a high degree of contamination of food, the presence of bacteria such as Klebsiella spp., Escherichia coli, Salmonella spp., As well as parasitic contamination and mold grow thin the form of mold and yeast in most of the samples, both from public markets, the private trade. Note that according to the results indicated that food becomes, a vehicle of disease transmission to people, so it is essential, to have an adequate preparation to make this food suitable for human consuption mode.
\end{abstract}

Keywords: Meat, Microorganism, Contamination.

* Bruna Soares de Almeida, Faculdade Leão Sampaio, Rua Leão XIII, 02, Salesianos - Juazeiro do Norte, Ceará; CEP: 63051-280; e-mail: almeidabrunasoares@gmail.com 


\section{INTRODUÇÃO}

A carne bovina é a principal fonte de proteína animal consumida pela população brasileira, onde a média de consumo desse alimento tem aumentado a cada ano nas últimas décadas ${ }^{1}$. Além da rica constituição proteica, outros nutrientes como ácidos graxos, vitaminas e gorduras tornam a carne bovina um alimento essencial da dieta humana ${ }^{2}$.

Principal derivado cárneo, a carne moída, como preconiza a legislação brasileira, é obtida a partir da moagem de pedaços de carne previamente resfriados e isenta de partes e/ou aditivos, que venham a prejudicar a sua qualidade 3 .

A carne moída apresenta um elevado potencial de proliferação de patógenos, por ser obtido de restos de outras carnes, passar por um longo processo de manipulação em seu preparo e algumas vezes permanecer expostas à venda em temperatura inadequada ${ }^{4}$.

Com o objetivo de garantir a saúde do consumidor, a portaria 304/96 do ministério da agricultura estabelece regras sobre as condições de temperatura e higiene desde o processo de abate dos bovinos, até a embalagem e distribuição da carne e seus derivados, como também de diversos alimentos para o comércio ${ }^{5}$.

Consideradas um grave problema de saúde pública na atualidade, as doenças alimentares estão relacionadas com as etapas de manipulação e preparo dos alimentos, pois na maioria dos casos se observa uma elevada deficiência de higiene por parte dos manipuladores de alimentos ${ }^{6}$.

Doenças alimentares podem trazer diversas consequências para a saúde humana, variando de acordo com o agente etiológico, quantidade de microrganismo ingerido e de acordo com a susceptibilidade, idade e sexo do paciente ${ }^{7}$.

Os microrganismos que vierem a se desenvolver em produtos cárneos, podem ser provenientes de várias fontes, pois os mesmos passam por um longo processo de manipulação até seu preparo, não descartando a possibilidade de surgimento de microrganismos quando $\mathrm{o}$ acondicionamento é feito de maneira incorreta ${ }^{8}$.

Os manipuladores de alimentos são os principais responsáveis pela contaminação de alimentos por microrganismos, pois participam de todas as etapas de produção do mesmo, podendo essa acontecer nas fases de: preparo, acondicionamento, distribuição, ou ainda no momento do consumo ${ }^{9}$.

As feiras livres se destacam como os principais locais de comércio da carne e seus derivados, no entanto, esses locais, em sua maioria, são conhecidos por apresentarem uma elevada deficiência higiênico sanitária, o que acarreta riscos à saúde da população ${ }^{10}$.

Presente na sociedade desde a antiguidade os mercados públicos constituem uma importante fonte de intercâmbio de diversas mercadorias, contribuindo com a sustentabilidade e desenvolvimento econômico da região onde se localizam. Atualmente estes estabelecimentos estão passando por um processo de adaptação tecnológica para suas estratégias de mercado frente aos concorrentes, que são principalmente frigoríficos de grande porte ${ }^{11}$.

Por sua vez, os frigoríficos e os mercados de grande porte buscam garantir a disponibilidade frequente de seus produtos através de acordos comerciais entre si, ou ainda, em algumas vezes, diretamente com o produtor, garantindo com isso disponibilidade frequente de mercadorias aos consumidores e conseguindo manter uma relativa liderança frente a outros estabelecimentos que negociam com diversos fornecedores ${ }^{\mathbf{1 2}}$.

Visando alertar a população sobre a importância de um alimento saudável para manutenção da saúde humana, este trabalho tem como objetivo avaliar a qualidade microbiológica da carne moída comercializada no município de Juazeiro do Norte- Ceará.

\section{METODOLOGIA}

O estudo caracterizou-se como analítico e descritivo com abordagem qualitativa, desenvolvido em carnes moídas comercializadas no município de Juazeiro do Norte, CE. Foram coletadas 12 amostras, 6 amostras coletadas em diferentes pontos de vendas dos três 
principais mercados públicos e 6 amostras coletadas em seis frigoríficos privados do município de Juazeiro do Norte-CE. Os pontos de coleta foram escolhidos de forma aleatória. As amostras foram transportadas em embalagens fornecidas pelos comerciantes $\mathrm{e}$ acondicionadas em isopor com gelo e levadas para o Laboratório de Microbiologia da Faculdade Leão Sampaio.

Para realização das análises, foi pesado $20 \mathrm{~g}$ da amostra, esta foi diluída em $100 \mathrm{~mL}$ de água destilada estéril e posteriormente, filtrada com auxílio de gaze estéril dobrada quatro vezes. O procedimento para a observação do crescimento e identificação das bactérias foi realizado com base nas normas da Agência Nacional de Vigilância Sanitária (ANVISA). Uma alçada da diluição de cada amostra foi inoculada em meio de enriquecimento Brain Heart Infusion (BHI) e incubada em estufa microbiológica a $37^{\circ} \mathrm{C}$ por $24 \mathrm{~h}$. Em seguida, alçadas deste inoculado foram semeadas nos meios de cultura Ágar Eosin Methylene Blue (EMB) e Ágar Salmonella-Shigella (SS), com o objetivo de identificar presuntivamente Escherichia coli, Klebsiella spp. e Salmonella spp.

Para avaliação da presença de fungos foi inoculada uma alçada da diluição de cada amostra em meio Ágar Saboraud e acondicionados em câmara úmida por um período de 5 a 7 dias. Após esse período foi observado o crescimento de leveduras e bolores.

A diluição filtrada de cada amostra, também foi submetida à técnica de Hoffman Modificado para análise parasitológica.

No momento da coleta das amostras foi preenchido um checklist para avaliar as condições higiênicas dos estabelecimentos comercializadores de carne.

\section{RESULTADOS E DISCUSSÕES}

Como resultado do checklist aplicado para avaliar as condições higiênicas dos estabelecimentos, observou-se que nos frigoríficos particulares $83,3 \%$ dos estabelecimentos apresentavam boas condições de higiene, enquanto que $16,7 \%$ apresentaram uma higiene ruim, enquanto que nos mercados públicos, $50 \%$ dos estabelecimentos apresentaram boas condições de higiene e 50\% apresentavam deficiência na higienização.

Silva et al. ${ }^{13}$ em seu trabalho observou boas condições de higiene em 71,4\% dos estabelecimentos estudados e condições de higiene deficientes em 28,6\%, o que mostra uma coerência com os resultados do presente estudo.

Elias; Madrona ${ }^{14}$ destacam a importância da Análise de Perigos e Pontos Críticos de Controle (APPCC), e a adequação das Boas Práticas de Fabricação (BPF), em estabelecimentos produtores e de serviço alimentares, para obtenção de um alimento seguro e livre de contaminantes.

Observou-se que $50 \%$ dos estabelecimentos privados apresentavam lavatórios para as mãos, enquanto que nos mercados públicos apenas 16,7\%. Lundgren et al. $^{6}$ realizando trabalho semelhante em mercados públicos observou presença de lavatório para mãos em $16,7 \%$ dos estabelecimentos visitados, resultado semelhante ao encontrado no presente estudo. O mesmo também relatou que não foi observada a utilização desse recurso de higienização no momento da visita a esses boxes comerciais, resultados semelhantes ao constatado nessa pesquisa.

A RDC $275 / 02^{15}$ do Ministério da Saúde exige que todos os estabelecimentos disponham de vestuários, sanitários e banheiros, fator não observado nos estabelecimentos visitados nesta pesquisa.

Verificou-se que para o comércio da carne $100 \%$ dos frigoríficos privados e $33,3 \%$ dos mercados públicos utilizavam freezers para expor suas mercadorias. Essa diferença percentual pode ser explicada pelo hábito que os comerciantes possuem de expor seus produtos de forma mais visível aos clientes, fato semelhante ao observado por Almeida et al. ${ }^{16}$.

Analisando condições higiênico sanitárias em mercados públicos Lino et al. ${ }^{17}$ constatou que $99,17 \%$ dos comerciantes expunham os produtos para a venda em temperatura ambiente, o que mostra resultados compatíveis entre os dois estudos. A temperatura de armazenamento da carne moída resfriada conforme 
preconiza a legislação brasileira deve ser de $0{ }^{\circ} \mathrm{C}$ a $4{ }^{\circ} \mathrm{C}$ e a da carne moída congelada máxima de $-18{ }^{\circ} \mathrm{C}^{3}$.

Quanto ao tipo de tábua utilizada para corte da carne observou-se nos mercados públicos que $50 \%$ dos estabelecimentos não fazia uso desse equipamento, $33,3 \%$ utilizavam tábua de madeira e $16,7 \%$ de polietileno.

Nos frigoríficos privados obteve-se que $83,3 \%$ desses estabelecimentos não utilizam nenhum tipo de tábua, enquanto que em $16,7 \%$ era feito o uso de tábua de madeira.

Abreu; $\mathrm{Cabral}^{18}$ pesquisando enterobactérias em tábuas de madeira identificou sete tipos desses microrganismos, e afirma que as tábuas de madeira estão propícias ao surgimento de fissuras durante seu uso, possibilitando a aderência de bactérias a sua superfície.

Nos estabelecimentos que não se observou a utilização de nenhum tipo de tábua para corte da carne, este processo era realizado no próprio balcão de comércio e na maioria dos casos será notável a deficiência higiênica.

Conforme mostra a tabela 1 , foi observado que $100 \%$ dos vendedores de mercados públicos não faziam uso de equipamentos de proteção individual, enquanto que em pontos comerciais particulares observou-se a utilização de alguns desses itens.

Tabela 1: Porcentagem de utilização de Equipamentos de Proteção Individual pelos vendedores dos estabelecimentos visitados.

\begin{tabular}{cccccc}
\hline MP & SIM (\%) & NÁ (\%) & MPR & SIM (\%) & NÁO (\%) \\
Luva & - & 100 & Luva & 16,7 & 83,3 \\
Touca & - & 100 & Touca & 16,7 & 83,3 \\
Jaleco/avental & - & 100 & Jaleco/avental & 66,7 & 33,3 \\
Calçado fechado & - & 00 & Calçado & 16,7 & 83,3 \\
& & & fechado & \\
\hline
\end{tabular}

A utilização de equipamentos de proteção individual é a primeira regra para que os vendedores de carne possam garantir medidas de biossegurança tanto para si próprios como para os consumidores. Quando comparado o uso de EPI's pelos comerciantes de mercados públicos e estabelecimentos privados, observase a não utilização desses equipamentos pelos primeiros.

Em estudo avaliando as condições higiênico sanitárias de comércio de carnes em feiras livres,
Almeida et al. ${ }^{16}$ visitou 24 pontos de venda e verificou que nenhum dos manipuladores utilizavam as vestimentas e os EPI's necessários. De acordo com a legislação brasileira em vigor, o manipulador de alimentos deve trajar roupas, batas e luvas ${ }^{3}$ adequadas.

Como os manipuladores estão em contato direto com o alimento e/ou sua matéria prima, existe uma grande possibilidade de estarem relacionadas com a contaminação alimentar, pois a falta de informação sobre os riscos de doenças alimentares é a principal deficiência do setor de manipulação de alimentos ${ }^{19}$.

Tanto as amostras provenientes de mercados públicos quanto as de frigoríficos particulares apresentaram odor e coloração normais, mesmo nos casos em que o produto não estava sendo mantido sob refrigeração, isto pode ser explicado por ter ocorrido o abate do animal no mesmo dia que foram realizadas as coletas das amostras.

Em trabalho semelhante Baptista et al. ${ }^{20}$ analisando 20 amostras de carne bovina observou $20 \%$ de coloração normal e $75 \%$ de odor característico. O mesmo não relata sobre o tempo que o produto estava exposto para o comércio.

Essa diferença percentual na coloração observada nesses trabalhos pode ser explicada pela diferença de tempo que as carnes ficaram expostas à temperatura ambiente. Conforme constatado por Campos $^{21}$, a exposição da carne ao ar faz com que o pigmento desoximioglobina transforme-se em axiomioglobina, alterando a coloração da carne.

Segundo Mazzuchetti; Batalha ${ }^{22}$ pessoas de todas as classes sociais consideram a coloração normal da carne como o maior indicador de qualidade desse produto.

Nas 12 amostras analisadas foi constatada contaminação parasitológica em $91,7 \%$ das mesmas. Destoante do esperado observou-se uma maior contaminação em amostras de estabelecimentos privados, no qual todas as amostras apresentaram positividade para algum parasito, enquanto que em mercados públicos obteve-se que 16,7 \% das amostras apresentaram resultado negativo. 
Tabela 2: Parasitas encontrados em amostras de carne de mercados públicos e frigoríficos privados.

Endolimar nana Entamoeba coli Entamoebahistolytica Giardia spp

$\begin{array}{llllllll}\text { Amostras } & \text { MPU } & \text { MPR } & \text { MPU } & \text { MPR } & \text { MPU } & \text { MPR } & \text { MPUMPR }\end{array}$

\begin{tabular}{ccccccccc} 
Amostras & MPU & MPR & MPU & MPR & MPU & MPR & MPUMPR \\
\hline 1 & + & + & - & - & + & - & - & - \\
2 & + & - & - & - & + & + & + & - \\
3 & + & + & - & - & - & + & - & - \\
4 & - & - & - & + & - & + & - & - \\
5 & + & + & - & - & - & + & - & - \\
6 & + & + & - & - & - & + & + & - \\
\hline
\end{tabular}

Foi detectada uma elevada quantidade de parasitas tanto em amostras de mercados públicos como de mercados privados, o que comprova a deficiência higiênica desses estabelecimentos, uma vez que a transmissão dessas enteroparasitoses, na maioria das vezes, se dá por via fecal-oral, é mais frequente em locais com condições sanitárias deficientes ${ }^{23}$.

Nolla e $\operatorname{Cantos}^{24}$ em um trabalho sobre enteroparasitoses em manipuladores de alimentos, afirmam que a transmissão de doenças alimentares está ligada as condições da matéria prima, a má higienização do ambiente e aos maus hábitos dos manipuladores.

Conforme destaca Orlandi et al. ${ }^{25}$, dentre os parasitas encontrados merecem destaque Giardia spp.e Entamoebahistolytica, pela capacidade de produção de estruturas parasitárias infectantes.

$\mathrm{Na}$ análise microbiológica de Escherichia coli (E. coli) foi observada uma maior porcentagem desse microrganismo em amostras provenientes de mercados públicos, enquanto que a prevalência de Klebsiella spp. foi maior em amostras originadas de frigoríficos privados.

Verificou-se que $100 \%$ das amostras de estabelecimentos públicos apresentaram positividade para Salmonella spp. já nas amostras de comércios particulares foi detectada uma positividade de apenas $16,7 \%$.

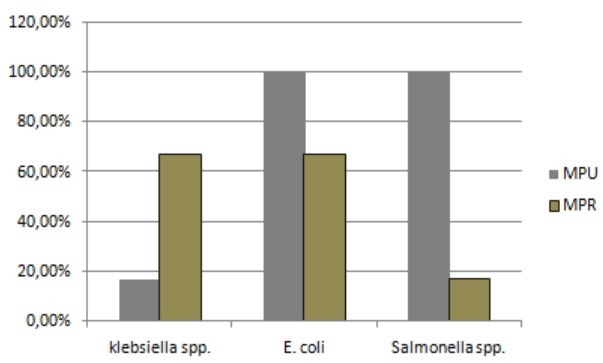

$\mathrm{MPU}=$ Mercado público $\mathrm{MPR}=$ Mercado privado

Gráfico 1: Porcentagem de Klebsiella spp., E. coli e Salmonella spp. nas amostras analisadas.
Observou-se a presença de E. coli em $100 \%$ das amostras coletadas de mercados públicos e em 66,7\% das amostras de frigoríficos privados. As melhores condições higiênico-sanitárias dos estabelecimentos privados fazem com que as amostras desses locais apresentem um menor grau de contaminação quando comparadas a amostras originadas de estabelecimentos públicos.

Silvestre et al. $^{26}$ encontrou coliformes termotolerantes em $100 \%$ das amostras de carne bovina in natura analisadas, fator este que vem a confirmar a que a contaminação por $E$. coli em carne moída pode vir a ocorrer antes do processo de moagem.

Para a análise de Klebsiella spp.observou-se uma maior contaminação por esse microrganismo nos estabelecimentos privados em relação aos públicos, com $66,7 \%$ e $16,7 \%$ respectivamente.

Rezende et al. $^{27}$ realizando análise microbiológica em superfícies inanimadas e utensílios onde se manipulam alimentos, encontrou valores significativos de Klebsiella spp. em bancadas e tábuas para corte. Considerando esses resultados pode-se relacionar a presença desse microrganismo com a contaminação ocorrida durante a manipulação.

A presença de Salmonella spp. apresenta uma diferença considerável entre as amostras oriundas de mercados públicos e as de mercados privados. As amostras desses estabelecimentos apresentaram um percentual de positividade para a Salmonella spp. de $100 \%$ e $16,7 \%$ respectivamente.

Essa diferença nos resultados pode ser explicada em parte pela relativa diferença nas condições higiênicas dos estabelecimentos e pelo percentual de uso de EPI's pelos manipuladores de alimentos, que foi observada com maior frequência nos estabelecimentos particulares.

Welker et al. ${ }^{28}$ analisando alimentos envolvidos em surtos alimentares no Rio Grande do Sul, verificou que a Salmonella spp. foi o microrganismo mais encontrado com 37\%, e que entre os alimentos analisados os produtos cárneos foram os que apresentaram um maior percentual de envolvimento com os surtos dessas doenças, sendo detectada a contaminação desse alimento em $37 \%$ dos casos. 
De acordo com Sigarini et al. ${ }^{29}$ a presença desse microrganismo em produtos cárneos é considerado um fator preocupante para a saúde do consumidor e demonstra uma não adesão às normas higiênicas que precisam ser seguidas durante a manipulação de alimentos. Vale ressaltar que a legislação brasileira, de acordo com a RDC $275 / 02^{15}$ da Agência Nacional de Vigilância Sanitária (ANVISA), considerada a carne e seus derivados próprios para o consumo humano quando estes produtos apresentarem ausência de Salmonella spp. em 25 gramas.

$\mathrm{Na}$ análise fúngica, nas formas de bolor e leveduras, constatou-se uma maior presença nas amostras obtidas de pontos comerciais de mercados públicos, conforme está listado na tabela 3.

Tabela 3 - Distribuição percentual dos tipos de fungos encontrados nas amostras obtidas de mercados públicos e frigorificos privados.

\begin{tabular}{ccc}
\hline Tipo de fungo & Mercado público (\%) & Frigorífico privado (\%) \\
Bolor & $100 \%$ & $66,7 \%$ \\
Leveduriforme & $100 \%$ & $50 \%$ \\
\hline
\end{tabular}

Em um estudo realizando três coletas em dias diferentes em uma unidade de alimentação Kochanski et $\mathrm{al}^{30}$, observou o crescimento de bolores e leveduras em todas as amostras analisadas, no entanto, observou que houve uma diminuição na quantidade de colônias fúngicas quando utensílios e equipamentos do setor de alimentação foram substituídos por equipamentos novos.

No presente estudo observou-se que as amostras de mercados públicos apresentaram uma positividade maior para os dois tipos de fungos pesquisados, o que evidencia mais uma vez a importância da adoção de medidas higiênicas adequadas como meio de prevenir a contaminação de alimentos no local de comércio.

\section{CONSIDERAÇÕES FINAIS}

As análises realizadas mostraram coesão com a literatura que relata a carne moída bovina como um alimento propenso a sofrer contaminação microbiana. Os resultados encontrados classificam esse produto como veículo de transmissão de doenças alimentares se não preparados de maneira adequada para o consumo.
A presença de Salmonella spp. verificada em algumas amostras, classificam as mesmas como impróprias para o consumo humano, de acordo com a legislação brasileira para análise de microrganismos em alimentos.

Contudo, estudos mais detalhados devem ser realizados para investigar em qual etapa do processo de manipulação esse alimento está sendo contaminado e traçar a forma mais adequada de prevenção microbiológica, com o objetivo de obter um alimento seguro para o consumo.

\section{REFERÊNCIAS}

1. BRASIL, ABIEC (Associação Brasileira da Indústria Exportadora de Carne Bovina), 2006. Disponível em: http://www.abiec.com.br/estatísticas.html. Acesso em 28 de Agosto de 2014.

2. SILVA, A.P; CORDÃO, M.A; ARAÚJO, V.J.A; SILVA, L.C.A; GOMES, A.A.B; CARVALHO, M.G.X. Avaliação microbiológica de carne bovina (chã de dentro) comercializada no município de Patos, PB. Higiene alimentar, 2011.

3. BRASIL. Ministério da Agricultura, Pecuária e abastecimento. Instrução Normativa $n^{\circ} 83$, de 21 de novembro de 2003. Aprova os Regulamentos Técnicos de Identidade e Qualidade de Carnes Bovina em Conserva (CornedBeef) e Carne Moída. Brasília, DF. 2003.

4. NASCIMENTO, M.V.D; PAZ, M.C.F; Avaliação da qualidade microbiológica da carne moída fresca comercializada no mercado central em Campina Grande-PB. IX Congresso de iniciação científica da Universidade Federal de Campina Grande, 2011.

5.

RASIL. Ministério da Saúde. Agência Nacional de Vigilância Sanitária. Portaria n. 304, de 22 de Abril de 1996. Estabelece critérios para introdução de modificações nas atividades de distribuição e comercialização de carne bovina, bubalina e suína, visando à saúde do consumidor. Diário Oficial da República Federativa do Brasil, Brasília, DF, 23 de abril de 1996. Seção 01, p.6856. Disponível em: http://www.anvisa.gov.br/e-legis/. Acesso em 24 de Setembro de 2014.

6. LUNDGREN, P.U; SILVA, J.A; MACIEL, J.F; FERNANDES, T.M; Perfil da qualidade 
higiênico-sanitária da carne bovina comercializada em feiras livres e mercados públicos de João Pessoa/PB-Brasil. Alimentos e Nutrição Araraquara, v. 20 n. 1, 2009.

7. TAVARES, T.M; SERAFINI, A.B. Carnes de hambúrgueres prontas para consumo: Aspectos legais e riscos bacterianos. Patologia tropical, v.35, 2006.

8. GOMES, P.M.A; BARBOSA, J.G; JUNIOR, I.G.S; Avaliação das condições higiênicas sanitárias das carnes comercializadas na feira livre do município de Catolé do Rocha-PB. Revista verde de Agroecologia e Desenvolvimento Sustentável, v.7, 2012.

9. LIMA, A.W.O; SOUSA, C.P. Infecções e intoxicações alimentares. In: Aspectos da ciência e tecnologia de alimentos. João Pessoa, PB: Nova idéia, 2002.

10. CRUZ, C. H.G; HOFFMANN, F. Leite; BUENO, S. M. Monitoramento microbiológico de lanches vendidos por ambulantes na parte central da cidade de Säo José do Rio Preto, SP. Hig. aliment, v. 14, 2000.

11. PINTAUDI, S. M. Os mercados públicos: metamorfoses de um espaço na história urbana. Scripta Nova. Revista Electrónica de Geografía y CienciasSociales, v. 10, 2007.

12. FERREIRA, G. C; PADULA, A. D. Estrutura produtiva e competitividade da cadeia da carne bovina no Rio Grande do Sul. Encontro anual da anpad, v. 22, 1998.

13. SILVA, G.R; BARROS,M.L.G; BARBOSA, M.V.F; SIQUEIRA, M.G.F.M; OLIVEIRA, A.E; LINS, L.F; MOURA, A.P.B.L. Percepção do conceito de higiene e segurança alimentar dos manipuladores de produtos cárneos de mercado público, Recife-PE, Acta veterinária Brasílica, v.7, 2013.

14. ELIAS, A. H; MADRONA, G. S. Avaliação de uma indústria produtora de embutidos cárneos quanto à higiene e legislação vigente no Brasil. Revista Brasileira de Tecnologia Agroindustrial, v. 2, n. 2, 2008.

15. BRASIL. Ministério da Saúde. Agência Nacional de Vigilância Sanitária. Regulamento técnico sobre procedimentos operacionais padronizados aplicados aos estabelecimentos produtores/industrializadores de alimentos e a lista de verificação das boas práticas defabricação em estabelecimentos produtores/industrializadores de alimentos. Diário Oficial da República Federativa do Brasil, Brasília, 06 de Novembro de 2002.
16. ALMEIDA, R.B; DINIZ, W.J.S; SILVA, P.T.V; ANDRADE, L.P; DINIZ, W.P.S; LEAL, J.B.G; BRANDESPIM, D.F; Condições higiênico-sanitárias da comercialização de carnes em feiras livres de Paranatama, PE. Alimentos e Nutrição. Araraquara, v. 22, 2011.

17. LINO, G.C; PACHECO, M.S; ROLIM, M.B.Q; PAIVA, J.N; MOURA, A.P.B.L; Condições higiênico-sanitárias dos estabelecimentos de comercialização de carnes nos Mercados Públicos de Jaboatão dos Guararapes, PE. Medicina Veterinária, v.3, 2009.

18. ABREU, S. C; CABRAL, M.M.W. Análises microbiológicas de placas de corte de madeira para identificação de bactérias pertencentes ao grupo das enterobacteriaceae. Revista Científica da Universidade de Franca (SP) v.5, 2009.

19. ANDREOTI, A; BALERONI; F.H; PAROSCHI, V.H.B; PANZA, S.G.A.A; Importância do treinamento para manipuladores de alimentos em relação à higiene pessoal. Iniciação Científica, Cesumar, v.5, 2003.

20. BAPTISTA, R.I.A.A; MOURA, F.M.L; FERNANDES, M.F.T.S; SANTOS, V.V.M; FERNANDES, E.F.T.S; aspectos qualitativos da carne moída comercializada na região metropolitana do Recife-PE. Acta Veterinária Brasílica, v.7, 2013.

21. CAMPOS, L; Suplementação dietética em vitamina $E$, e qualidade da carne bovina. Disponível em http://www.beefpoint.com.br/cadeiaprodutiva/si c/suplementação-dietética-em-vitamina-e -equalidade-da-carne-bovina. Acesso em 28 de Outubro de 2014.

22. MAZZUCHETTI, R.N; BATALHA, M.O; O comportamento do consumidor em relação ao consumo e às estruturas de comercialização da carne bovina na região de Amerios/PR. Varia scientia. v.20, 2004.

23. SOARES, B; CANTOS, G.A; Qualidade parasitológica e condições higiênico sanitárias de hortaliças comercializadas na cidade de Florianópolis, Santa Catarina, Brasil. R. bras. Epid. 2005.

24. NOLLA, A.C; CANTOS, G. A Relação entre a ocorrência de enteroparasitoses em manipuladores de alimentos e aspectos epidemiológicos em Florianópolis, Santa Catarina, Brasil. 2005.

25. ORLANDI P.A, CHU, M.T, BIER, J.W, JACKSON J.G. Parasites and the food supply. Foodtechnology, 2002. 
26. SILVESTRE, M.K.S; ABRANTES, M.R; PAIVA, W.S; SOUZA, E.S; SILVA, J.B.A. Avaliação da qualidade da carne bovina in natura comercializada no município de Alexandria-RN. Acta veterinária Brasílica, v.7, 2013.

27. REZENDE, C; SEEMANN, C.F; SIVLA, E.S; JACOBUCCI, H.B; MATTAR,M. Superfície inanimada-possível fonte de contaminação microbiológica no alimento. Rev. Bras. Farm, v. 93, 2012.

28. WELKER, C.A.D; BOTH, J.M.C; LONGARAY, S. M; HAAS, S; SOEIRO, M.L.T; RAMOS, R.C;Análise microbiológica dos alimentos envolvidos em surtos de doenças transmitidas por alimentos (DTA) ocorridos no estado do Rio Grande do Sul, Brasil. Revista Brasileira de Biociências. v. 8, 2010.

29. SIGARINI, C.O; OLIVEIRA, L.A.T; FRANCO, R.M; FIGUEIREDO, E.E.S; CARVALHO, J.C.A.C; Avaliação bacteriológica da carne bovina desossada, em estabelecimentos comerciais do município de Cuiabá, MT, Higiene Alimentar. 2006.

30. KOCHANSKI, S; PIEROZAN, M.K; MOSSI, A.J; TREICHEL, H; CANSIAN, R.L; GHISLENI, C.P; TONIAZZO, G; Avaliação das condições microbiológicas de uma unidade de alimentação e nutrição. 2009. 